\title{
DOSSIÊ: VIOLÊNCIA EM CONTEXTO ESCOLAR E ESCOLA EM CONTEXTO VIOLENTO
}

\section{FATORES QUE AFETAM A PRÁTICA DE VIOLÊNCIA POR ALUNOS DENTRO DO AMBIENTE ESCOLAR NO ESTADO DE MINAS GERAIS}

\section{MAICKER LEITE BARTZ}

Doutorando em Economia Aplicada no Programa de Pós-Graduação em Economia Aplicada da Universidade Federal de Viçosa - PPGEA/UFV. E-mail: maickerbartz@gmail.com

\section{EWERTON DA SILVA QUARTIERI}

Mestre em Economia Aplicada pelo Programa de Pós-Graduação em Economia Aplicada da Universidade Federal do Rio Grande - PPGE/FURG. E-mail: ewerton.quartieri@gmail.com

\section{VIVIAN DOS SANTOS QUEIROZ ORELLANA}

Professora permanente do Programa de Pós-Graduação em Economia Aplicada da Universidade Federal do Rio Grande PPGE/FURG. E-mail: viviansq13@gmail.com

\section{RESUMO}

Este trabalho investiga os principais fatores internos e externos que influenciam a violência cometida por alunos dentro de escolas do estado de Minas Gerais. As escolas são um ambiente de ensino e aprendizado voltado para ргерагаг o aluno para a inserção em sociedade, mas o crescente aumento da violência urbana tem influenciado o comportamento delinquente dentro das escolas. Para avaliar a probabilidade de um aluno cometer agressão na escola estimou-se um modelo logit usando os dados da Prova Brasil de 2011. Os resultados apontam que agressão de professor, furto e atentado à vida são as variáveis do ambiente escolar que mais elevam a probabilidade de o aluno cometer uma agressão dentro da escola. O mesmo se observa para as variáveis externas, especialmente tráfico de drogas. Já o investimento em segurança e vigilância na escola não se mostram suficientes para mitigar o problema, pois são medidas de combate imediato à violência escolar que precisa de ações que envolvam apoio social, como a interação entre escola e comunidade.

Palavras-chave: Violência escolar; agressão; Minas Gerais; modelo logit.

\section{ABSTRACT \\ FACTORS AFFECTING VIOLENCE PRACTICE BY STUDENTS IN THE SCHOOL ENVIRONMENT IN THE STATE OF MINAS GERAIS}

This paper investigates internal and external factors which influence the violence committed by students in schools in the State of Minas Gerais. The Schools are a teaching and learning environment designed to prepare the student for social inclusion, but the mounting in urban violence has influenced delinquent behavior in schools. In order to evaluate the probability of a student committing aggression in school, a logit model was estimated using the data from Prova Brasil of 2011. The results indicate that teacher aggression, theft and life attempt are the variables of the school environment, which increase the most the probability of the student to commit an aggression in the school. The same goes for external variables, especially drug trafficking. On the other hand, the investments in school safety and 
Fatores que afetam a prática de violência por alunos dentro do ambiente escolar no estado de Minas Gerais Maicker Leite Bartz , Ewerton da Silva Quartieri e Vivian dos Santos Queiroz Orellana

surveillance are not sufficient to mitigate the problem, once they are measures of immediate combat against school violence, which requires actions involving social support, such as the interaction between school and community. Keywords: School violence; agression; Minas Gerais; logit.

DOI: 10.31060/rbsp.2019.v13.n2.982

Data da Submissão: 29/07/2018 - Data de aprovação : 16/07/2019

\section{INTRODUÇÃO}

A ocorrência de violência nas escolas é uma das principais chagas contemporâneas que se reflete em um grande problema social, principalmente no Brasil, onde as taxas de criminalidade são muito elevadas. No entanto, a violência não está mais limitada às ruas, ela está cada vez mais inserida no ambiente escolar, que deveria proteger contra a criminalidade e a violência urbana, mas acaba se tornando um espaço para práticas de atos agressivos pelos agentes do setor educacional (ABRAMOVAY; RUA, 2003).

De acordo com Leite (2008 apud UNESCO, 2003, p. 5), a violência pode ser entendida como "todo e qualquer ato de agressão, seja física, moral ou institucional, dirigido contra a integridade de um ou vários indivíduos". A violência no meio escolar prejudica o aprendizado e aumenta a probabilidade de o jovem se envolver em criminalidade quando adulto (FARRINGTON, 1990; TEIXEIRA; KASSOUF, 2015; BECKER; KASSOUF, 2016). Ainda que o indivíduo não ingresse na vida criminosa, estar exposto de maneira precoce a atos violentos tem como consequência traumas que podem perdurar toda a vida (OMS, 2002).

O comportamento violento do aluno dentro da escola geralmente é uma resposta aos impulsos internos como ameaças e agressões físicas ou verbais cometidas por alunos ou professores, destruição do patrimônio, uso de drogas, furtos, etc. (SPOSITO, 2001; ALLEN et al., 2006). Além disso, os elevados índices de criminalidade e violência urbana que favorecem o tráfico de drogas e a formação de gangues no entorno das escolas acabam se deslocando para o ambiente interno e exercem forte influência na agressividade dos alunos (UNESCO, 2003).

A educação, por sua vez, tem o poder de exercer direta e indiretamente a função de mitigar a violência com a formação do capital humano do cidadão, o desenvolvimento do sentido de moralidade do aluno e a preparação para a entrada na sociedade (ARAUJO JUNIOR; FAJNZYLBER, 2000). Porém, a educação também pode ser fonte de exclusão social quando as melhores oportunidades de trabalho requerem maior qualidade de ensino. Desse modo, os alunos podem ser excluídos do sistema educacional por baixo aprendizado, o que prejudica a inserção no mercado de trabalho e acentua a exclusão social (ABRAMOVAY; RUA, 2003; LEITE, 2008).

A investigação do comportamento agressivo dos alunos dentro das escolas do Brasil ganhou relevância a partir de 1990 com vários estudos da Unesco em parceria com pesquisadores e instituições. O estudo realizado por Abramovay (1999) para cidades da periferia de Brasília foi realizada em conjunto com a Unesco. A pesquisa acadêmica desenvolvida por Guimarães (1998) focou no papel da criminalidade do entorno das escolas públicas do Rio de Janeiro, enquanto Costa (2005) e Leite (2008) realizaram um levantamento de informações sobre as escolas de Belo Horizonte para entender a violência escolar na região e sugerir medidas para seu combate.

Diante do exposto, este artigo tem por objetivo investigar quais são os principais propulsores internos e externos às escolas que aumentam a probabilidade de um aluno cometer um ato de agressão dentro das 
instituições de ensino no estado de Minas Gerais. Para tanto, são usados dados da Prova Brasil de 2011 e um modelo de probabilidade logit. Busca-se, assim, contribuir com a literatura ao aplicar um método empírico para analisar os referidos dados, que trazem informações sobre as ocorrências de atos violentos e criminosos em várias escolas do Brasil e sobre a estrutura dos estabelecimentos de ensino. Minas Gerais é o segundo maior estado em termos relevância na amostragem de escolas dentro da Prova Brasil e a escolha se dá exatamente por essa representatividade dentro da pesquisa, sendo de suma importância para o entendimento deste fenômeno para a região.

A escola possui um papel fundamental na formação do estudante, tanto por representar boa parte da sua formação de cidadania quanto por ser um ambiente de convivência que possui uma rede de influência no seu comportamento. É necessária a criação de um conjunto de mecanismos capazes de transformar os jovens a fim de reduzir a prática de violência tanto na escola quanto fora dela. Assim, as informações produzidas nesse estudo poderão contribuir para a formulação de projetos sociais voltados a reduzir o problema de violência nas escolas em Minas Gerais.

Além desta introdução, o trabalho está dividido em mais quatro seções. A seguir apresenta-se o referencial teórico sobre o comportamento dos alunos e seus fatores de impacto. Na sequência exibe-se a metodologia e os tratamentos da base de dados. A seção subsequente discute os resultados e seguemse as considerações finais.

\section{MEIO DE INFLUÊNCIA E COMPORTAMENTO AGRESSIVO}

A literatura econômica focada na violência dá valor essencial ao papel da educação na nascente de relações de distúrbios sociais que envolvam agressões e problemas deste tipo (ARAUJO JUNIOR; FAJNZYLBER, 2000; CERQUEIRA; LOBÃO, 2004), tratando pela ótica de que o indivíduo carrega para a fase adulta o estigma de uma má educação, o que pode afetar seu comportamento perante a sociedade. Em tese, quanto menor o seu grau de instrução, menos custoso torna-se um ato desviante, tendo em vista sua possível deficiência no desenvolvimento de suas habilidades - o que poderia representar maior renda na fase adulta - e seu desenvolvimento moral, fatores que deveriam desestimular comportamentos socialmente não aceitos. Desta forma, o agente se coloca como um avaliador de seu benefício líquido ao considerar os custos incumbidos de agir em transgressão, como na Teoria da Escolha Racional proposta por Becker (1968). A presente investigação procura captar, em partes, o comportamento transgressor em jovens dentro do ambiente escolar e suas implicações dentro de sua formação, levantando neste tópico contextos que ajudem a entender este fenômeno pouco explorado na literatura brasileira, conforme evidencia Sposito (2001).

Segundo argumentam Martins, Machado e Furlanetto (2016), os canais influenciadores do comportamento contraventor no ambiente escolar são de ordem interna e externa à escola. Entre os fatores externos se destaca a fragilidade vivenciada pelos jovens em ordem socioeconômica e cultural, que se associam a situações de exposição à violência nas comunidades onde eles vivem; influência dos grupos de referência; preconceitos e práticas de bullying. Assim, os fatores internos referentes à escola ganham importância, necessitando que se crie um ambiente saudável por parte de todos os responsáveis competentes para evitar que os alunos sofram com situações de insegurança e marginalização (MARTINS; MACHADO; FURLANETTO, 2016).

Granero et al. (2011), em estudo realizado para a Venezuela, destacam o problema da redução de frequência escolar dos jovens estudantes que são expostos à violência. Menor frequência escolar pode 
Fatores que afetam a prática de violência por alunos dentro do ambiente escolar no estado de Minas Gerais Maicker Leite Bartz , Ewerton da Silva Quartieri e Vivian dos Santos Queiroz Orellana

acarretar pior desempenho, o que pode constituir, conforme discutido anteriormente, um agravante para a inserção futura no mercado de trabalho e ocasionar exclusão social (ABRAMOVAY; RUA, 2003; LEITE, 2008). No Brasil, Macedo e Bomfim (2009) identificam que a sensação de insegurança contextual no ambiente escolar está relacionada a fatores como a presença de gangues e sensação de insegurança dentro da escola e no seu entorno; onde tanto alunos como professores atestam que o ambiente de sala de aula apresenta situações de violência.

A influência dos pares no comportamento dos jovens é algo que demanda atenção, visto que grupos de relação apresentam condutas semelhantes na fase de formação de jovens. Akers (1998) e Allen et al. (2006) argumentam que os pares são o principal fator de influência nos hábitos dos indivíduos na transição da infância para a adolescência, esta é a fase de vida em que uma pessoa mais assimila a atuação de pares e amigos nas suas práticas. Assink et al. (2015) utilizam um levantamento de meta-análise para sustentar a ideia de que a associação entre pares em diversos tipos comportamentais pode indicar uma trajetória permanente no papel exercido pelos indivíduos. Brumley e Jaffee (2016) indicam que associações com pares delinquentes influenciam atos de delinquência nos indivíduos ao longo da formação. Farrel, Thompson e Mehari (2017) encontram na literatura evidências sobre a importância da aprovação pelos pares para os jovens, que reagem não somente por influência do comportamento agressivo de seus amigos próximos, mas também por julgarem que seria essa a conduta aprovada pelos pares.

Wolff e Baglivio (2017) relatam que jovens expostos a maus-tratos na sua formação estrutural tendem a reagir de forma a perpetuar ações de violência e trauma. Aqueles que sofreram situações frustrantes ou hostis e apresentam maior dificuldade em lidar com suas emoções tendem a reincidir em comportamentos violentos. Entre os fatores que afetam de forma indireta a reincidência em práticas delinquentes, os jovens fragilizados apresentam motivações "frias" (distúrbios psicológicos devidos aos traumas causados por maustratos) e "quentes" (a necessidade de responder ao ambiente de influência de maneira autoafirmativa). Destaque-se a importância de políticas que visem controlar distúrbios traumáticos, com a oferta de atividades que permitam aos jovens expor e entender seu comportamento, por meio de terapia em que os potenciais delinquentes possam lidar com as fontes dos seus desvios de comportamento (WOLFF; BAGLIVIO, 2017).

Welsh (1978) trata da importância negativa da escola na propagação de atos de delinquência através do que ele chama de medidas restritivas. O autor considera que uma iniciativa e abordagens agressivas por parte do corpo de funcionários da instituição escolar sejam um catalisador para que os alunos externem comportamentos agressivos nas suas demais interações sociais. Moon et al. (2015) argumentam, amparados na literatura sobre a Teoria Geral da Tensão, que práticas delinquentes em jovens se mostram, em parte, associadas com atitudes agressivas e abusivas de professores. Os autores realizam um levantamento com 777 estudantes sul-coreanos e apontam que medidas de violência física ou emocional praticadas por professores afetam de forma direta desvios no comportamento dos alunos.

Grogger (1997) avança no sentido de indicar como a violência escolar afeta, de fato, o desempenho dos alunos envolvidos neste ambiente. Ao analisar o caso dos Estados Unidos, o autor encontra atraso no desempenho dos estudantes no sentido de diminuir sua frequência às aulas. Outros estudos encontram resultados similares, como os de Henrich et al. (2004), Ratner et al. (2006), McGarvey et al. (2006), Carroll (2006) e Ammermueller (2007).

Trazendo o debate para o Brasil, Becker e Kassouf (2016) utilizam um modelo logístico para avaliar a probabilidade de os alunos cometerem atos violentos, dado o ambiente onde estão inseridos. As autoras 
inferem maior probabilidade de os estudantes executarem práticas agressivas se a escola apresentar problemas de infraestrutura em relação aos alunos de uma instituição que não apresente tais problemas. O estudo também verificou uma probabilidade 3,54 vezes maior de um aluno cometer uma infração violenta se no seu ambiente escolar vivenciar um professor cometendo um ato de violência contra outro membro do corpo de trabalho da escola.

Tavares e Pietrobom (2016) avaliam fatores associados ao problema da violência escolar utilizando dados da Secretaria da Educação do Estado de São Paulo que agrupam características das escolas, corpo de funcionários de educação, alunos e familiares de alunos. Os resultados encontrados pelas autoras apontam que os delitos cometidos por agentes externos às escolas estão associados às condições socioeconômicas do entorno das instituições, além da qualidade da sua gestão. Já os delitos cometidos por agentes internos estão diretamente relacionados à composição social e demográfica do corpo discente, sendo estes resultados mais interessantes para contextualizar o escopo deste trabalho.

Bartz, Quartieri e Freitas (2017) analisam uma recente base de dados com informações de diversos atos violentos ocorridos nas escolas públicas do Rio Grande do Sul. Devido à falta de informações sobre as características das escolas, os autores, num estudo preliminar, criam indicadores de violência e indisciplina, caracterizando as principais escolas e regiões com incidência mais elevada dos atos analisados. Concluem que as escolas mais violentas do Rio Grande do Sul estão presentes na Região Metropolitana de Porto Alegre, sendo esta a região mais violenta do estado. Isso pode significar que a violência urbana presente nesses municípios tenha influência nas ocorrências escolares.

Este estudo busca contextualizar o fenômeno da violência no ambiente escolar com possíveis fatores de propagação deste se embasando no trabalho de Becker e Kassouf (2016). Buscando representar o efeito da atuação dos pares utilizaram-se variáveis capazes de captar a presença de violência praticada por algum aluno ou professor, fator explicitado anteriormente como uma possível fonte de propagação de mais violência pelos indivíduos fragilizados por esse ambiente. Além disso, verificaram-se problemas ocasionados por agentes estranhos à escola, ou seja, não identificados como alunos ou membros do corpo de funcionários, que são fatores de caráter externo, porém, que também são propagadores de tensão e sensação de insegurança envolvendo o ambiente escolar, tais como atentado à vida de algum membro escolar, presença de gangues, tráfico de drogas, depredação e furto. Por fim, testaram-se medidas tidas como de contenção e combate a distúrbios violentos. Estes pontos estão mais bem detalhados na próxima sessão.

\section{METODOLOGIA}

O modelo logit, de modo diferente dos modelos lineares padrão, trabalha com uma variável dependente de resposta binária, um resultado qualitativo, distinto da análise de resultado quantitativo dos modelos convencionais linearizados onde o y (a variável de interesse) assume valores aleatórios de um número finito. No modelo de resposta binária, a variável dependente y assume os valores 1 ou 0 , indicando respectivamente a ocorrência ou não ocorrência da hipótese testada. Logo, o interesse nos modelos de resposta binária está no fato de que a análise principal reside na probabilidade $p$ de $y$ assumir a resposta de sucesso, $y=1$, ou de fracasso, $y=0$ (WOOLDRIDGE, 2010):

$$
p \equiv P(y=1 \mid X)=G(x \beta)
$$


Fatores que afetam a prática de violência por alunos dentro do ambiente escolar no estado de Minas Gerais

Em que $x$ é o vetor de covariadas; $\beta$ é o vetor de parâmetros; $G(x \beta$ ) é uma função de distribuição acumulada que possibilita à probabilidade assumir valores entre 0 e 1 para todos os valores de $x$ (WOOLDRIDGE, 2010).

Рara a probabilidade de um aluno cometer agressão, caso em que $y=1$, a equação (1) pode ser representada por um modelo logit, que considera uma função de distribuição acumulada logística da seguinte forma:

$$
G(z)=\frac{1}{1+e^{-z}}=\frac{e^{z}}{1+e^{-z}}
$$

De forma que a equação (2) representa a probabilidade de o evento ocorrer $(y=1)$, enquanto a chance de o evento não ocorrer $y=0$ é:

$$
G(z)=1-\frac{e^{z}}{1+e^{-z}}=\frac{1}{1+e^{-z}}
$$

O modelo logit tem a vantagem de poder calcular a razão de chances (odds ratio) ou taxa relativa de risco, $P / 1-P$, que mensura a probabilidade de o evento ocorrer $y=1$ relativo à probabilidade de não ocorrer $y=0$ e pode ser obtido a seguir:

$$
\begin{aligned}
& \frac{P}{1-P}=\frac{1+e^{Z}}{1+e^{-Z}}=e^{Z} \\
& L=\ln \left(\frac{p}{1-p}\right)=Z
\end{aligned}
$$

A equação (5) mostra que o modelo é um log-odds ratio, ou seja, é linear nos regressores. A interpretação dos resultados do modelo logit não leva em conta a magnitude dos coeficientes estimados, mas apenas o sentido da associação entre as variáveis dependente e explicativas, já as odds ratio (equações 4 ou 5) podem ser interpretadas como uma variação unitária em um regressor na própria odds ratio por $100\left(\exp \left(\beta_{j}\right)-1\right)$. Por exemplo, se $100\left(\exp \left(\beta_{j}\right)-1\right)=10 \%$, então um aumento unitário em uma variável explicativa eleva em $10 \%$ a relação de probabilidade.

A vantagem de escolha do modelo logit é justamente por considerar na sua previsão a probabilidade de ocorrência de determinado evento, sendo apropriado para esta análise, em que o interesse recai sobre a interação das variáveis independentes sobre a probabilidade da ocorrência do evento de violência por parte dos alunos, considerando como comparação o caso onde a resposta positiva da interação dessas variáveis não ocorre.

A estimação do modelo logit é feita através do Método da Máxima Verossimilhança (MV) (GREENE, 2003). O interesse na estimação por MV condicional é a obtenção da função de log da probabilidade para cada i, assumindo que existam $\mathrm{N}$ informações que são independentes e identicamente distribuídas. Para isso, trata-se a função de densidade para $y$ dado $x$, de forma:

$$
f\left(y \mid x_{i} ; \beta\right)=\left[G\left(x_{i} \beta\right)\right]^{y}\left[1-G\left(x_{i} \beta\right)\right]^{1-y}, y=0,1
$$

Assim, a função linearizada de probabilidade fica:

$$
l_{i}(\beta)=y_{i} \log [G(z)]+\left(1-y_{i}\right) \log [1-G(z)]
$$


Fatores que afetam a prática de violência por alunos dentro do ambiente escolar no estado de Minas Gerais

Maicker Leite Bartz , Ewerton da Silva Quartieri e

Vivian dos Santos Queiroz Orellana

Em que a função $G(z)$ assume apenas valores entre 0 e 1 e garante que $l_{i}(\beta)$ seja bem definido para todos os coeficientes estimados (WOOLDRIDGE, 2010).

O log da probabilidade para um espaço amostral N é definido como:

$$
L(\beta)=\sum_{i}^{N}=1 l_{i}(\beta)
$$

Sendo o estimador de MV, $\hat{\beta}$ o estimador que maximiza o log da probabilidade trabalhada. De forma geral, o estimador de MV do $\hat{\beta}$ é consistente e assintoticamente normal (WOOLDRIDGE, 2010). Рara o caso do modelo logit em questão, o $\hat{\beta}$ é o estimador que maximiza a função de distribuição acumulada logística de forma igual a (2), $G(z)=\frac{e^{z}}{1+e^{-z}}$.

\section{BASE DE DADOS E TRATAMENTOS}

Os dados utilizados neste artigo são referentes ao questionário das escolas e dos diretores da Prova Brasil de 2011. A Prova Brasil é organizada pelo Instituto Nacional de Estudos e Pesquisas Educacionais Anísio Teixeira (Inep), que é uma autarquia do Ministério da Educação (MEC). A avaliação é realizada bianualmente, e é aplicada a alunos de $5^{\circ}$ e último ano do ensino fundamental. Além da prova, são aplicados quatro questionários, sendo para alunos, professores, diretor e um com informações da escola. Deixa-se claro que os últimos dados disponíveis da Prova são de 2015, no entanto, a Prova de 2011 possui uma gama de variáveis mais detalhadas que as provas posteriores, por isso optou-se por utilizá-la.

Na Tabela 1 são descritas as variáveis utilizadas no trabalho. Todas as variáveis são binárias, assumido valor 0 ou 1, conforme pode ser conferido a seguir. No Quadro 1 identificam-se as variáveis, o questionário a que pertencem, o número da questão e sua descrição. Quanto à variável agressão de professor, a construção partiu da junção de perguntas do questionário do diretor. Uma pergunta era se houve agressão de algum professor a algum outro professor, e outra se o caso foi contra um funcionário. Logo, a variável de agressão de professor assumiu valor 1 se houve pelo menos uma das duas ou as duas agressões pela parte do professor, e 0 se nenhuma das duas ocorreu. A construção das outras variáveis seguiu a mesma lógica.

Partindo do suposto de que os indivíduos baseiam suas decisões em detrimento das pessoas a sua volta, segundo teoria de Heavner e Lochner (2002), foi incluída a variável de agressão do professor com o objetivo de medir se um comportamento agressivo do professor influencia o aluno. Essa variável caracteriza as escolas onde houve agressão de algum professor dentro da escola contra algum colega ou funcionário. Conforme o proposto por Heavner e Lochner (2002), espera-se que a conduta dos professores funcione como balizador das decisões dos alunos, logo, no momento em que um professor comete algum ato violento, o aluno pode se sentir motivado a fazer o mesmo. No entanto, se um aluno possui um comportamento agressivo em sala de aula, isso pode motivar a reação do professor, havendo causalidade reversa, conforme argumentam Becker e Kassouf (2016). Por isso, não foram consideradas as agressões de professores a alunos, mas apenas contra outros professores e funcionários.

Com o intuito de tentar captar o ambiente escolar e sua influência no comportamento do aluno, foram usadas variáveis de ocorrências de atentado à vida, furto e depredação, além de presença de tráfico de drogas e de gangues nas escolas. Esse conjunto de variáveis tem como causador da ação algum agente externo à escola, ou seja, não é um aluno nem funcionário, e sim uma pessoa sem vínculo com a instituição. 
Fatores que afetam a prática de violência por alunos dentro do ambiente escolar no estado de Minas Gerais Maicker Leite Bartz , Ewerton da Silva Quartieri e

Esse é um ponto importante, pois a ocorrência de algum desses atos pode influenciar o comportamento dos alunos, no entanto, é pouco provável que o comportamento do agente externo seja influenciado por algum ato violento cometido por um aluno. Caso fossem considerados os atos de crime e depredação referentes aos agentes internos, ou seja, alguém com vínculo com a escola, haveria a possibilidade, novamente, de um caso de causalidade reversa.

Ainda foram incluídas quatro variáveis com objetivo captar as medidas e ações que as escolas tomam para reduzir a violência no meio escolar. Uma delas serve para identificar as escolas que desenvolvem algum tipo de atividade extracurricular, justificada pela importância de propor um melhor ambiente aos alunos, criando um espaço agradável de integração e promoção cultural. Além disso, com o intuito de retirar a hipótese de convivio de alunos com idades muito distintas, usa-se a variável que identifica as escolas que formam turmas conforme idade. Por fim, foram utilizadas duas variáveis - medidas de segurança e vigilância - com o objetivo de captar a tentativa da escola de reduzir o contato dos alunos com a violência.

\section{QUADRO 1}

\begin{tabular}{|c|c|c|c|}
\hline Variável & Questionário & Questão & Descrição \\
\hline Agressão por aluno & Diretor & $\begin{array}{l}\text { União das } \\
\text { questões } 180 \\
182 \text { e } 184\end{array}$ & $\begin{array}{l}\text { Houve agressão física de um aluno a professores, } \\
\text { funcionários ou outro aluno. Sim -1; Não-0 }\end{array}$ \\
\hline $\begin{array}{l}\text { Agressão por } \\
\text { professor }\end{array}$ & Diretor & $\begin{array}{l}\text { União das } \\
\text { questões } 186 \\
\text { e } 190\end{array}$ & $\begin{array}{l}\text { Houve agressão física de um professor a } \\
\text { professores ou funcionários. Sim-1; Não-0 }\end{array}$ \\
\hline Atentado à vida & Diretor & $\begin{array}{l}\text { União das } \\
\text { questões } 133 \\
\text { e } 134\end{array}$ & $\begin{array}{l}\text { Houve atentado à vida de algum professor, } \\
\text { funcionário ou aluno (agente estranho à escola). } \\
\text { Sim-1; Não-0 }\end{array}$ \\
\hline Tráfico de drogas & Diretor & $\begin{array}{l}\text { União das } \\
\text { questões } 152 \\
\text { e } 153\end{array}$ & $\begin{array}{l}\text { Houve ocorrência de tráfico nas dependências } \\
\text { externas ou internas da escola (agente estranho } \\
\text { à escola). Sim-1; Não-0 }\end{array}$ \\
\hline Gangues & Diretor & $\begin{array}{l}\text { União das } \\
\text { questões } 177 \\
\text { e } 178\end{array}$ & $\begin{array}{l}\text { Houve atuação de gangues nas dependências } \\
\text { externas ou internas da escola (agente estranho } \\
\text { à escola). Sim-1; Não-0 }\end{array}$ \\
\hline Depredação & Diretor & $\begin{array}{l}\text { União das } \\
\text { questões } 143 \\
147 \text { e } 148\end{array}$ & $\begin{array}{l}\text { Houve depredação das dependências externas } \\
\text { ou internas da escola (agente estranho à escola). } \\
\text { Sim- } 1 \text {; Não-0 }\end{array}$ \\
\hline Furto & Diretor & $\begin{array}{l}\text { União das } \\
\text { questões } 135 \\
\text { e } 136\end{array}$ & $\begin{array}{l}\text { Houve ocorrência de furto a professores ou } \\
\text { alunos nas dependências da escola (agente } \\
\text { estranho à escola). Sim-1; Não-0 }\end{array}$ \\
\hline $\begin{array}{l}\text { Atividade } \\
\text { extracurricular }\end{array}$ & Diretor & $\begin{array}{l}\text { União das } \\
\text { questões } 114 \\
\text { e } 115\end{array}$ & $\begin{array}{l}\text { A escola desenvolve atividades extracurriculares } \\
\text { (esporte ou artes). Sim-1; Não-0 }\end{array}$ \\
\hline $\begin{array}{l}\text { Segurança no } \\
\text { entorno }\end{array}$ & Escola & Questão 36 & $\begin{array}{l}\text { A escola adota alguma medida de segurança } \\
\text { para proteger os alunos nas suas imediações. } \\
\text { Sim-1; Não-0 }\end{array}$ \\
\hline Vigilância & Escola & $\begin{array}{l}\text { União das } \\
\text { questões } 26,27 \\
\text { e } 28\end{array}$ & $\begin{array}{l}\text { Há algum tipo de vigilância para o período } \\
\text { diurno, noturno ou finais de semana. Sim-1; } \\
\text { Não-0 }\end{array}$ \\
\hline Turma por idade & Diretor & Questão 33 & Turmas formadas por idade. Sim-1; Não-0 \\
\hline
\end{tabular}


Fatores que afetam a prática de violência por alunos dentro do ambiente escolar no estado de Minas Gerais

Maicker Leite Bartz , Ewerton da Silva Quartieri e

Vivian dos Santos Queiroz Orellana

\section{RESULTADOS}

A base de dados da Prova Brasil apresenta limitação, pois apenas identifica a presença ou ocorrência de determinada ação e não o número de ocorrências, ou seja, os dados utilizados nesse trabalho apenas representam se houve ou não a presença de determinado ato na escola.

A Tabela 1 traz as estatísticas descritivas da amostra utilizada após a exclusão dos valores missing e recortes, totalizando 4572 escolas do estado de Minas Gerais. Quanto às variáveis, por se tratarem de variáveis binárias - ou são 0 ou 1 -, a média de cada uma representa a ocorrência da variável, ou seja, em $43,43 \%$ das escolas da amostra ocorreram agressões de alunos, em apenas $1,46 \%$ das escolas ocorreram agressões de professores, e assim por diante.

\section{TABELA 1}

\section{Média e desvio padrão de variáveis sobre violência no ambiente escolar.}

Minas Gerais, 2011.

\begin{tabular}{|l|c|c|c|c|}
\hline Variável & Média & Desvio padrão & Mínimo & Máximo \\
\hline Agressão por aluno & 0,4343 & 0,4957 & 0 & 1 \\
\hline Agressão por professor & 0,0146 & 0,1201 & 0 & 1 \\
\hline Atentado à vida & 0,0726 & 0,2595 & 0 & 1 \\
\hline Tráfico de drogas & 0,3641 & 0,4812 & 0 & 1 \\
\hline Gangues & 0,1719 & 0,3773 & 0 & 1 \\
\hline Depredação & 0,2812 & 0,4496 & 0 & 1 \\
\hline Furto & 0,2338 & 0,4233 & 0 & 1 \\
\hline Atividade extracurricular & 0,9048 & 0,2934 & 0 & 1 \\
\hline Segurança no entorno & 0,4606 & 0,4985 & 0 & 1 \\
\hline Vigilância & 0,5174 & 0,4997 & 0 & 1 \\
\hline Turma por idade & 0,2839 & 0,4509 & 0 & Fonte: Prova Brasil 2011. Elaborado pelos autores. \\
\hline
\end{tabular}

Na Tabela 2 é possível visualizar a relação de ocorrência de agressão física por alunos com as outras variáveis. Em 62,69\% das escolas onde foi registrada agressão física por um professor, ocorreu também agressão física por parte dos alunos. O resultado para as outras variáveis é interpretado da mesma maneira, ou seja, em escolas onde ocorreram casos de furto, atentado à vida, depredação, tráfico de drogas ou atuação de gangues, a porcentagem de casos de agressão física por alunos é maior em comparação às escolas nas quais não ocorreram ações que caracterizam um ambiente escolar violento.

Já as escolas com formação de turmas por idade, atividades extracurriculares, medidas de segurança e vigilância apresentam uma porcentagem menor de ocorrência de casos de agressão por alunos, na comparação com as escolas onde essas características não são verificadas. Esses resultados servem para identificar o sinal esperado para cada uma das variáveis. 
Fatores que afetam a prática de violência por alunos dentro do ambiente escolar no estado de Minas Gerais Maicker Leite Bartz , Ewerton da Silva Quartieri e

TABELA 2

Distribuição das escolas, por condição de ocorrência de agressão por alunos, segundo variáveis sobre violência no ambiente escolar.

Minas Gerais, 2011.

\begin{tabular}{|c|c|c|c|}
\hline \multirow{2}{*}{ Variáveis } & & \multicolumn{2}{|c|}{ Agressão cometida por aluno } \\
\hline & & Sim & Não \\
\hline \multirow{2}{*}{ Agressão por professor } & $\operatorname{sim}$ & $62,69 \%$ & $37,31 \%$ \\
\hline & กão & $43,15 \%$ & $56,85 \%$ \\
\hline \multirow{2}{*}{ Atentado à vida } & $\operatorname{sim}$ & $66,87 \%$ & $33,13 \%$ \\
\hline & กão & $41,60 \%$ & $58,40 \%$ \\
\hline \multirow{2}{*}{ Tráfico de drogas } & $\operatorname{sim}$ & $60,78 \%$ & $39,22 \%$ \\
\hline & กão & $33,50 \%$ & $66,50 \%$ \\
\hline \multirow{2}{*}{ Gangues } & $\operatorname{sim}$ & $65,78 \%$ & $34,22 \%$ \\
\hline & กão & $38,80 \%$ & $61,20 \%$ \\
\hline \multirow{2}{*}{ Depredação } & $\operatorname{sim}$ & $57,39 \%$ & $42,61 \%$ \\
\hline & กão & $37,98 \%$ & $62,02 \%$ \\
\hline \multirow[b]{2}{*}{ Furto } & $\operatorname{sim}$ & $60,05 \%$ & $39,95 \%$ \\
\hline & กão & $38,37 \%$ & $61,63 \%$ \\
\hline \multirow{2}{*}{ Turma por idade } & $\operatorname{sim}$ & $45,53 \%$ & $54,47 \%$ \\
\hline & กão & $42,61 \%$ & $57,39 \%$ \\
\hline \multirow{2}{*}{ Atividade extracurricular } & $\operatorname{sim}$ & $43,49 \%$ & $56,51 \%$ \\
\hline & กão & $42,99 \%$ & $57,01 \%$ \\
\hline \multirow{2}{*}{ Vigilância } & $\operatorname{sim}$ & $44,80 \%$ & $55,20 \%$ \\
\hline & กล̃o & $41,98 \%$ & $58,02 \%$ \\
\hline \multirow{2}{*}{ Segurança no entorno } & $\operatorname{sim}$ & $41,88 \%$ & $58,12 \%$ \\
\hline & กล̃o & $44,77 \%$ & $55,23 \%$ \\
\hline
\end{tabular}

Fonte: Prova Brasil 2011. Elaborado pelos autores.

A Tabela 3 apresenta os resultados da estimação do modelo logit e odds ratio. O grau de ajustamento do modelo logit foi medido pelo count $\mathrm{R}^{2}$ da estimativa, que serve para auferir o número de acertos do modelo. O resultado encontrado foi de $64,35 \%$ dos valores preditos. Ainda por meio do mesmo teste, é possível analisar a sensibilidade e a especificidade do modelo. Basicamente esses dois resultados servem para ver o percentual de acertos positivos (predições de ocorrência de agressão) e negativos (predições de não ocorrência de agressão) do modelo. Para o caso das predições de ocorrência de agressão, o resultado foi de $44,01 \%$ de acerto, e para os casos de não ocorrência foi de 79,97\%.

Os resultados da Tabela 3 mostram que a agressão cometida por professor aumenta em $60 \%$ a probabilidade de os alunos cometerem alguma agressão na escola. Segundo a teoria da interação social, o comportamento individual depende da relação do indivíduo com a sua rede social de contatos (FREEMAN, 1999). Dessa forma, os jovens baseiam as suas decisões no comportamento das pessoas ao seu redor, considerando-os como modelo de conduta. Esse resultado está de acordo com os principais estudos da literatura (ABRAMOVAY; RUA, 2003; LEITE, 2008).

As variáveis que caracterizam o ambiente interno e externo da escola com a presença de violência, como crime contra o patrimônio (depredação), crime contra pessoa (atentado à vida e furto), furto nas dependências das escolas, tráfico de drogas e atuação de gangues foram estatisticamente significativas a $1 \%$ e apresentam sinal positivo. 
Fatores que afetam a prática de violência por alunos dentro do ambiente escolar no estado de Minas Gerais

Maicker Leite Bartz, Ewerton da Silva Quartieri e

Vivian dos Santos Queiroz Orellana

Nas escolas onde aconteceram depredações, a probabilidade de um aluno cometer agressão aumentou em proximamente 35\%. Os crimes de atentando à vida e furto também aumentaram a probabilidade de ocorrência de agressões por parte dos alunos em, respectivamente, 48\% e 56\%. Já a presença de gangues nas proximidades da escola aumentou a probabilidade de agressão por parte do aluno em torno de 59\%, enquanto o tráfico de drogas elevou substancialmente essa probabilidade em $116 \%$. As gangues são grupos de sociabilidade que não se formam necessariamente dentro das escolas e representam a necessidade de autoafirmação através da prática de violência por parte de jovens que sofrem algum tipo de estigma (SPOSITO, 2001). Segundo Abramovay e Rua (2003), o clima de insegurança e medo ocasionado pelas gangues e o tráfico de drogas levam à perda de autoridade pelos professores e diretores das escolas, que temem repreensões, o que acaba fomentando ainda mais a violência interna praticada pelos alunos.

\section{TABELA 3}

Resultados do modelo logit e odds ratio por condição de ocorrência de agressão por alunos, segundo variáveis sobre violência no ambiente escolar.

Minas Gerais, 2011.

\begin{tabular}{|c|c|c|}
\hline Variáveis & $\begin{array}{l}(1) \\
\text { Logit }\end{array}$ & $\begin{array}{c}\text { (2) } \\
\text { Odds ratio }\end{array}$ \\
\hline \multicolumn{3}{|l|}{ Variáveis internas } \\
\hline \multirow{2}{*}{ Agressão por professor } & $0,472 *$ & $1,604 *$ \\
\hline & $(0,440)$ & $(0,440)$ \\
\hline \multirow{2}{*}{ Depredação } & $0,298 * * *$ & $1,348 * * *$ \\
\hline & $(0,103)$ & $(0,103)$ \\
\hline \multirow{2}{*}{ Furto } & $0,444 * * *$ & $1,559 * * *$ \\
\hline & $(0,125)$ & $(0,125)$ \\
\hline \multirow{2}{*}{ Atentado à vida } & $0,391 * * *$ & $1,479 * * *$ \\
\hline & $(0,201)$ & $(0,201)$ \\
\hline \multirow{2}{*}{ Turma por idade } & 0,025 & 1,026 \\
\hline & $(0,0716)$ & $(0,0716)$ \\
\hline \multicolumn{3}{|l|}{ Variáveis externas } \\
\hline \multirow{2}{*}{ Tráfico de drogas } & $0,771 * * *$ & $2,163 * * *$ \\
\hline & $(0,156)$ & $(0,156)$ \\
\hline \multirow{2}{*}{ Gangues } & $0,466 * * *$ & $1,594 * * *$ \\
\hline & $(0,152)$ & $(0,152)$ \\
\hline \multicolumn{3}{|c|}{ Medidas de combate à violência } \\
\hline \multirow{2}{*}{ Segurança no entorno } & $-0,107 *$ & $0,898^{*}$ \\
\hline & $(0,0573)$ & $(0,0573)$ \\
\hline \multirow{2}{*}{ Atividade extracurricular } & $-0,145$ & 0,865 \\
\hline & $(0,0918)$ & $(0,0918)$ \\
\hline \multirow{2}{*}{ Vigilância } & 0,069 & 1,072 \\
\hline & $(0,0685)$ & $(0,0685)$ \\
\hline \multirow{2}{*}{ Constante } & $-0,719 * * *$ & $0,487 * * *$ \\
\hline & $(0,0538)$ & $(0,0538)$ \\
\hline Observações & 4.572 & 4.572 \\
\hline
\end{tabular}


Fatores que afetam a prática de violência por alunos dentro do ambiente escolar no estado de Minas Gerais Maicker Leite Bartz , Ewerton da Silva Quartieri e Vivian dos Santos Queiroz Orellana

Entre as variáveis de ações que visam reduzir a ocorrência de atos violentos nas escolas, como segurança no entorno, vigilância e participação em atividades extracurriculares, apenas a variável de segurança no entorno, que visa proteger os alunos nas imediações dos estabelecimentos de ensino, apresentou resultado estaticamente significativo e negativo. Assim, as escolas que apresentam medidas de segurança diminuem a probabilidade de os alunos cometerem violência em apenas $10 \%$. Mesmo que a segurança possa ter um papel importante na redução da marginalidade do entorno do ambiente da escola e dos atos violentos cometidos dentro da escola, ela por si só não é capaz de combater a violência de forma eficaz (LEITE, 2008; ABRAMOVAY; RUA, 2003).

A Tabela 4 apresenta as probabilidades de ocorrência de violência na escola para diferentes cenários. A primeira linha mostra que, ao utilizar a média de ocorrência de cada variável, a probabilidade de que uma escola apresente algum aluno que cometa um ato violento, $\operatorname{Pr}(y=1 \mid x)$, é de $43,20 \%$. Para o restante dos resultados é feita uma análise de variável em variável, ou seja, na segunda linha é visto o efeito de ocorrer agressão contra o professor, sem ocorrer nenhum dos outros atos. Na terceira linha considera-se que ocorreu agressão por professor e tráfico na escola, sem ocorrer nenhum dos outros atos, e assim por diante.

\section{TABELA 4}

\begin{tabular}{|c|c|}
\hline \multicolumn{2}{|l|}{ Probabilidades de ocorrência de violência escolar em diferentes cenários } \\
\hline Ocorrência & Probabilidade \\
\hline $\operatorname{Pr}(y=1 \mid x)$ & $43,20 \%$ \\
\hline $\operatorname{Pr}(y=1 \mid$ agressão por professor $)$ & $43,84 \%$ \\
\hline $\operatorname{Pr}(y=1 \mid$ agressão por professor e tráfico) & $62,81 \%$ \\
\hline $\operatorname{Pr}(y=1 \mid$ agressão por professor, gangues e tráfico) & $72,92 \%$ \\
\hline $\operatorname{Pr}(y=1 \mid$ agressão por professor, depredação, gangues e tráfico) & $78,40 \%$ \\
\hline $\operatorname{Pr}(y=1 \mid$ agressão por professor, furto, depredação, gangues, tráfico) & $84,98 \%$ \\
\hline $\operatorname{Pr}(y=1 \mid$ agressão por professor, atentado à vida, furto, depredação, gangues e tráfico) & $89,33 \%$ \\
\hline $\begin{array}{l}\operatorname{Pr}(y=1 \mid \text { agressão por professor, atentado à vida, furto, depredação, gangues e tráfico, } \\
\text { segurança) }\end{array}$ & $88,25 \%$ \\
\hline $\begin{array}{l}\operatorname{Pr}(y=1 \mid \text { agressão por professor, atentado à vida, furto, depredação, gangues e tráfico, } \\
\text { segurança, atividade extracurricular) }\end{array}$ & $86,66 \%$ \\
\hline $\begin{array}{l}\operatorname{Pr}(y=1 \mid \text { agressão por professor, atentado à vida, furto, depredação, gangues e tráfico, } \\
\text { segurança, atividade extracurricular, vigilância) }\end{array}$ & $87,44 \%$ \\
\hline $\begin{array}{l}\operatorname{Pr}(y=1 \mid \text { agressão por professor, atentado à vida, furto, depredação, gangues e tráfico, } \\
\text { segurança, atividade extracurricular, vigilância, turma por idade) }\end{array}$ & $87,72 \%$ \\
\hline $\operatorname{Pr}(y=1 \mid$ segurança, turma por idade, vigilância, atividade extracurricular) & $29,36 \%$ \\
\hline
\end{tabular}

Fonte: Prova Brasil 2011. Elaborado pelos autores.

A partir da Tabela 4, nota-se que à medida que o cenário da escola piora, a probabilidade de que haja uma escola com ocorrência de violência física praticada por um aluno aumenta. A última linha da Tabela 5 refere-se ao cenário em que só há mecanismos para reduzir a violência na escola, por exemplo, segurança no entorno e vigilância. Assim, é possível concluir que a probabilidade de ocorrência de violência na escola de $29 \%$ é menor do que em todos os outros casos, mais ainda é elevada, indicando que essas medidas não são as mais eficientes para reduzir a violência dentro da escola. 
Um outro resultado que corrobora a ideia de medidas ineficientes de combate à violência está nessa mesma tabela, em que se testam cenários onde ocorrem todos os atos violentos em conjunto com algumas medidas que poderiam ajudar a combater a violência. Quando ocorrem todos os atos violentos na escola, a probabilidade de que um aluno cometa algum ato violento é de $89,33 \%$, no entanto, à medida que ocorrem medidas de segurança, vigilância, etc., esses valores não se reduzem, ou seja, por mais que as escolas façam alguma ação que contribua para o combate à violência, se a instituição é muito violenta, o efeito na redução da violência não se mostra eficiente. Segundo Leite (2008), o investimento em segurança e vigilância na escola faz parte de um conjunto de ações imediatas de combate à violência escolar e preserva a crença de que a violência vem de fora da escola, sendo assim, é dada menor importância às ações sociais que preservam o envolvimento com a comunidade escolar.

Por fim, os resultados encontrados neste trabalho contribuem com a literatura ao evidenciarem empiricamente que os jovens respondem agressivamente às tensões vivenciadas no ambiente escolar e às características do seu entorno, e vão ao encontro da literatura internacional e nacional, como a teoria da tensão de Agnew (1992), Akers (1998) e Allen et al. (2006), Unesco (2003), Abramovay e Rua (2003), Leite (2008), Moon et al. (2015), Becker e Kassouf (2016), Brumley e Jaffee (2016).

\section{CONSIDERAÇÕES FINAIS}

Este estudo teve por objetivo avaliar a influência do meio escolar interno e externo na probabilidade de os alunos cometerem atos violentos na escola usando a base de dados da Prova Brasil de 2011 e um modelo de probabilidade logit. É importante ressaltar que o estudo visa contextualizar situações onde os jovens se desenvolvem de maneira agressiva com fatores que podem representar tais situações, sem apresentar intenção de causalidade até mesmo pela escolha da ferramenta estatística. Ainda assim, espera-se ter apresentado indicativos da interação entre o fato de um aluno cometer um ato de agressão com possíveis medidas que impulsionam ou mitigam este problema.

Os resultados apontaram que os fatores internos que elevam a probabilidade de o aluno cometer agressão na escola são principalmente agressividade dos professores dentro da escola, atentado à vida e furtos. Os alunos se espelhariam no comportamento violento de seus professores dentro da escola para cometer atos de violência também. Os fatores externos, especialmente o tráfico de drogas, elevaram a probabilidade de agressão pelo aluno na escola e tal situação poderia produzir um ambiente de medo nos professores e diretores, que não tomam atitudes contra a violência escolar. Já o investimento em segurança na escola não reduziu substancialmente o comportamento agressivo dentro da escola, pois esse tipo de ação imediatista de repreensão não afetaria diretamente o foco do problema.

Portanto, os resultados empíricos desse trabalho evidenciaram que o enfoque do combate à violência escolar deve ser as relações sociais. O aumento do comportamento delinquente nas escolas enfatiza que há uma fragilidade na estrutura familiar em transmitir valores morais e estabelecer regras (LEITE, 2008). Assim, o desenvolvimento de projetos sociais que envolvam comunidade e escola devem ser prioridade, visando aumentar o envolvimento da família na educação dos filhos e combater de forma mais eficaz a violência nas escolas. Também são importantes mais investimentos em equipamentos pedagógicos e em infraestrutura das escolas para auxiliar o desenvolvimento de projetos sociais e fortalecer a relação escola-aluno-família. 
Fatores que afetam a prática de violência por alunos dentro do ambiente escolar no estado de Minas Gerais Maicker Leite Bartz , Ewerton da Silva Quartieri e Vivian dos Santos Queiroz Orellana

\section{REFERÊNCIAS BIBLIOGRÁFICAS}

ABRAMOVAY, M. Gangues, galeras, chegados e rappers: juventude, violência e cidadania nas cidades da periferia de Brasília. Brasília: Editora Garamond, 1999.

ABRAMOVAY, M.; RUA, M. G. Violência nas escolas. Brasília: UNESCO, Coordenação DST/AIDS do Ministério da Saúde, Secretaria de Estado dos Direitos Humanos do Ministério da Justiça, CNPq, Instituto Ayrton Senna, UNAIDS, Banco Mundial, USAID, Fundação Ford, CONSED, UNDIME, 2002.

AGNEW, R. Foundation for a general strain theory of crime and delinquency. Criminology, v. 30, n. 1, p. 47-88, 1992.

AKERS, R. L. Social learning and social structure: a general theory of crime and deviance. Boston, Ma: Northeastern University Press, 1998.

ALLEN, J. P.; PORTER, M. R.; MCFARLAND, F. C. Leaders and followers in adolescent close friendships: susceptibility to peer influence as a predictor of risky behavior, friendship instability, and depression. Development and Psychopathology, v. 18, n. 1, p. 155-172, 2006.

AMMERMUELLER, A. Violence in European schools: victimization and consequences. Discussion Paper, Centre for European Economic Research (ZEW), Mannheim, Alemanha, p.1-40, 2007.

ARAUJO JUNIOR, A.; FAJNZYLBER, P. Crime e economia: Um estudo das microrregiões mineiras. Revista Econômica do Nordeste, v. 31, p. 630-659, 2000.

ASSINK, Mark et al. Risk factors for persistent delinquent behavior among juveniles: A meta-analytic review. Clinical psychology review, v. 42, p. 47-61, 2015.

BARTZ, M. L.; QUARTIERI, E. Da S.; DE FREITAS, T. A. Indisciplina e violência escolar: uma análise das escolas públicas do Rio Grande do Sul. Revista Estudo \& Debate, v. 24, n. 3, p. 241-263, 2017.

BECKER, G. S. Crime and punishment: An economic approach. The economic dimensions of crime. London: Palgrave Macmillan, 1968. p. 13-68.

BECKER, K. L.; KASSOUF, A. L. Violência nas escolas públicas brasileiras: uma análise da relação entre o comportamento agressivo dos alunos e o ambiente escolar. Nova Economia, v. 26, n. 2, p. 663-677, 2016.

BRUMLEY, L. D.; JAFFEE, S. R. Defining and distinguishing promotive and protective effects for childhood externalizing psychopathology: a systematic review. Social psychiatry and psychiatric epidemiology, v. 51, п. 6, p. 803-815, 2016.

CARROLL, B. The effects of school violence and crime on academic achievement. Davidson College, 2006.

CERQUEIRA, D.; LOBÃO, W. Determinantes da criminalidade: arcabouços teóricos e resultados empíricos.

Dados - Revista de Ciências Sociais, v. 47, n. 2, p. 233-269, 2004.

COSTA, P. R. Multiplicando os pontos de vista sobre a violência nas escolas: Estudo comparativo do clima escolar em duas escolas públicas de Belo Horizonte. 2005. Dissertação (mestrado em educação) Faculdade de Educação da Universidade Federal de Minas Gerais, Belo Horizonte, 2005.

FARRINGTON, D. P. Childhood aggression and adult violence: Early precursors end later-life outcomes. In: PEPPLER, J; RUBIN K. (Ed.). The development and treatment of childhood aggression. Toronto: Psychology Press, 1990. p. 5-25. 
FARRELL, A. D.; THOMPSON, E. L.; MEHARI, K. R. Dimensions of peer influences and their relationship to adolescents' aggression, other problem behaviors and prosocial behavior. Journal of youth and adolescence, v. 46, n. 6, p. 1351-1369, 2017.

FREEMAN, R. B. The economics of crime. Handbook of Labor Economics. Amsterdam: Elsevier Science, 1999.

GRANERO, R.; PONI, E.S.; ESCOBAR-PONI, B.C.; ESCOBAR, J. Trends of violence among 7th, 8th and 9th grade students in the state of Lara, Venezuela: The Global School Health Survey 2004 and 2008. Arch Public Health, v. 69, n. 1, p. 7, 2011.

GREENE, W. H. Econometric analysis. New York: Pearson Education India, 2003.

GROGGER, J. Local violence and educational attainment. Journal of Human Resources, Madison, v. 32, ก. 4, p. 659-682, 1997.

GUIMARÃES, M. E. Escola, galeras e narcotráfico. Rio de Janeiro: Editora da UFRJ, 1998.

HEAVNER, D. L.; LOCHNER, L. Social Networks and the Aggregation on Individual Decisions. National Bureau of Economic Research, 2002. Working Paper n. w8979.

HENRICH, C. C.; SCHWAB-STONE, M.; FANTI, K.; JONES, S. M.; RUCHKIN, V. The association of community violence exposure with middle-school achievement: a prospective study. Journal of Applied Developmental Psychology, v. 25, n. 3, p. 327-348, 2004.

LEITE, M. R. S. D. T. Projetos Sociais como Medida de Combate à Violência nas Escolas: Um Desafio Para o Setor Educacional Brasileiro. In: ENCONTRO DA ANPAD, 32, 2008, Rio de Janeiro. Anais do evento. Rio de Janeiro: ANPAD, 2008.

MACEDO, R.M.A.; BOMFIM, M.C.A. Violências na escola. Rev Diálogo Educ, v. 9, n. 28, p. 605-618, 2009.

MARTINS, A. M.; MACHADO, C.; FURLANETTO, E. C. Mediação de conflitos em escolas: entre normas e percepções docentes. Cadernos de Pesquisa, v. 46, n. 161, p. 566-592, 2016.

MCGARVEY, M.; SMITH, W. J; WALKER, M. B. The interdependence of school outcomes and school and neighborhood crime. Nebraska: Georgia State University, Department of Economics, 2006. Working Paper 07-19.

MOON, B. et al. Violence against teachers in South Korea: Negative consequences and factors leading to emotional distress. Violence and victims, v. 30, n. 2, p. 279-292, 2015.

OMS. World report on violence and health. Genebra: WHO, 2002.

RATNER, H. H.; CHIODO, L.; COVINGTON, C.; SOKOL, R. J.; AGER, J; DELANEY-BLACK, V. Violence exposure, IQ, academic performance, and children's perception of safety: evidence of protective effects. MerrillPalmer Quarterly, v. 52, n. 2, p. 264-287, 2006.

SPOSITO, M. P. Um breve balanço da pesquisa sobre violência escolar no Brasil. Educação e pesquisa, v. 27, п. 1, p. 87-103, 2001.

TAVARES, P. A.; PIETROBOM, F. C. Fatores associados à violência escolar: evidências para o Estado de São Paulo. Estudos Econômicos, v. 46, n. 2, p. 471-498, 2016.

TEIXEIRA, E. C.; KASSOUF, A. L. Impacto da violência nas escolas paulistas sobre o desempenho acadêmico dos alunos. Economia Aplicada, v. 19, n. 2, p. 221-240, 2015.

UNESCO. Lidando com a violência nas escolas: o papel da UNESCO/Brasil. Brasília, DF: Unesco, 2003. 
Fatores que afetam a prática de violência por alunos dentro do ambiente escolar no estado de Minas Gerais

WELSH, Ralph S. Delinquency, corporal punishment, and the schools. Crime \& Delinquency, v. 24, n. 3, p. 336-354, 1978.

WOLFF, K. T.; BAGLIVIO, M. T. Adverse childhood experiences, negative emotionality, and pathways to juvenile recidivism. Crime \& Delinquency, v. 63, n. 12, p. 1495-1521, 2017.

WOOLDRIDGE, J. M. Econometric analysis of cross section and panel data. Cambridge: MIT press, 2010.

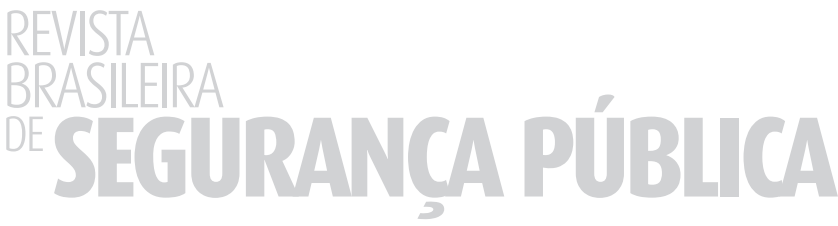

